\title{
Geographic variation in the response of Culex pipiens life history traits to temperature
}

\author{
Jordan E. Ruybal ${ }^{1 *}$, Laura D. Kramer ${ }^{2,3}$ and A. Marm Kilpatrick ${ }^{1}$
}

\begin{abstract}
Background: Climate change is predicted to alter the transmission of many vector-borne pathogens. The quantitative impact of climate change is usually estimated by measuring the temperature-performance relationships for a single population of vectors, and then mapping this relationship across a range of temperatures or locations. However, life history traits of different populations often differ significantly. Specifically, performance across a range of temperatures is likely to vary due to local adaptation to temperature and other factors. This variation can cause spatial variation in pathogen transmission and will influence the impact of climate change on the transmission of vector-borne pathogens.

Methods: We quantified variation in life history traits for four populations of Culex pipiens (Linnaeus) mosquitoes. The populations were distributed along altitudinal and latitudinal gradients in the eastern United States that spanned $\sim 3^{\circ} \mathrm{C}$ in mean summer temperature, which is similar to the magnitude of global warming expected in the next $3-5$ decades. We measured larval and adult survival, development rate, and biting rate at six temperatures between 16 and $35^{\circ} \mathrm{C}$, in a common garden experiment.
\end{abstract}

Results: Temperature had strong and consistent non-linear effects on all four life history traits for all four populations. Adult female development time decreased monotonically with increasing temperature, with the largest decrease at cold temperatures. Daily juvenile and adult female survival also decreased with increasing temperature, but the largest decrease occurred at higher temperatures. There was significant among-population variation in the thermal response curves for the four life history traits across the four populations, with larval survival, adult survival, and development rate varying up to 45,79 , and $84 \%$ among populations, respectively. However, variation was not correlated with local temperatures and thus did not support the local thermal adaptation hypothesis.

Conclusion: These results suggest that the impact of climate change on vector-borne disease will be more variable than previous predictions, and our data provide an estimate of this uncertainty. In addition, the variation among populations that we observed will shape the response of vectors to changing climates.

Keywords: Climate change, West Nile virus, Thermal response, Vector-borne disease, Local adaptation, Reaction norm, Chikungunya virus, Dengue

\footnotetext{
*Correspondence: jordanruybal@gmail.com

'Department Ecology and Evolutionary Biology, University of California, Santa

Cruz, CA 95064, USA

Full list of author information is available at the end of the article
} 


\section{Background}

The impact of climate change on the transmission of vector-borne diseases is a hotly debated topic [1-6]. Early predictions suggested that climate change would increase the global burden of tropical diseases, such as malaria, as temperate regions warmed [7]. However, other researchers have argued that warming will also cause a decrease in transmission in some tropical regions which will become too hot, and this will result in a geographic shift in distribution but little change in overall disease burden $[8,9]$. Further, many have argued that changes in other factors such as socioeconomic development, land use, drug treatment and bed-net use will be more important than climate change in determining disease incidence, and that transmission will be limited in temperate regions by public health systems and highly developed living conditions (e.g. screened windows and air conditioning) [10].

An issue that has received far less attention, despite its potential impact, is variability in the response of vectors to temperature $[8,11]$. Determining the extent of variation in temperature responses, is necessary to predict current and future spatial variation in transmission of tropical vector-borne diseases such as dengue virus and malaria, and to determine the extent of uncertainty in model predictions [11]. If variation among vector populations exists, and the variation is strongly correlated with local thermal regimes (as would be expected if adaptation to local temperatures were the strongest driver), then this variation could be incorporated into model predictions. However, organisms are simultaneously under a diverse set of selective pressures, and selection on life history traits from other factors, as well as drift, could result in unpredictable variation [12, 13]. Several studies have found either inverse or countergradient variation (a phenomenon in which variation in genotypes counteracts environmental influences across a gradient such that phenotypic variation is diminished) along temperature gradients [14], or significant variation, but little evidence of local thermal adaptation $[15,16]$. If variation among populations in the response to temperature is substantial, but idiosyncratic, then predictions of the impact of climate change will be far less accurate, and models should incorporate this additional source of uncertainty into the predictions.

Only a handful of studies have been conducted on local adaptation to temperature in mosquito vectors. In Anopheles gambiae, an important vector of malaria in Africa, populations along aridity and latitudinal clines in Cameroon and Nigeria had increased frequencies of a genetic trait (the 2La chromosomal inversion) that confers increased heat and desiccation tolerance [17-20]. In contrast, a study of two populations of Culex tarsalis in California did not find variation in life history traits that correlated with local temperatures [21]. Clearly, additional studies are needed of variation in vector traits that influence transmission from multiple populations along temperature gradients [11].

We examined spatial variation in life history traits of Culex pipiens mosquitoes along altitudinal and latitudinal gradients to determine the extent of local thermal adaptation. Cx. pipiens is the primary enzootic (bird-tobird) and bridge (bird-to-human) mosquito vector of West Nile Virus (WNV) and other arboviruses in urban and residential areas of North America north of approximately $36^{\circ}$ latitude [22-26], and a vector of WNV and Usutu virus in Europe [26-28]. WNV is a significant public health issue in North America, with $\sim 2.8$ million human infections, $>20,000$ cases of encephalitis and 1902 deaths since it was introduced in 1999 [29, 30]. Additionally, WNV has also killed millions of birds and caused regional declines in some species of up to $50 \%$ [31-33]. The wide geographic distribution of Cx. pipiens and its importance in transmitting several arboviruses makes it a useful model species to examine the extent of adaptation to local thermal regimes.

We conducted a common garden study of $C x$. pipiens mosquitoes from four populations along altitudinal and latitudinal gradients with average summer temperatures differing by $2-3{ }^{\circ} \mathrm{C}$ (Additional file 1: Figure S1). This variation in temperature is similar to that predicted to occur over the next few decades due to anthropogenic climate change [34]. We combined altitudinal and latitudinal gradients to generate temperature gradients with different confounding variables (e.g. day length, atmospheric pressure, etc.). We measured four life history traits: larval and adult survival, development rate, and biting rate, across a range of temperatures that spanned the seasonal climate of these four populations to characterize their performance along a thermal gradient. We hypothesized that high temperature populations (lower latitude and elevation) would experience selection for faster development rate, and increased survival at hotter temperatures, whereas colder populations would exhibit the opposite tradeoff $[35,36]$.

\section{Methods}

Study sites

We collected an average of $24.5(6,15,32$, and 45 rafts, respectively from the coolest to the warmest site) $C x$. pipiens egg rafts at each of four sites between July 25 and July 28, 2011 (Fig. 1b). Site names describe the latitude and/or elevation for each population relative to the low elevation/latitude population (Fig. 1b). Culex pipiens hybridize with Culex quinquefasciatus across a wide latitudinal band of North America [37, 38], and although previous genetic analyses in the study area found little evidence of Culex quinquefasciatus ancestry in these 


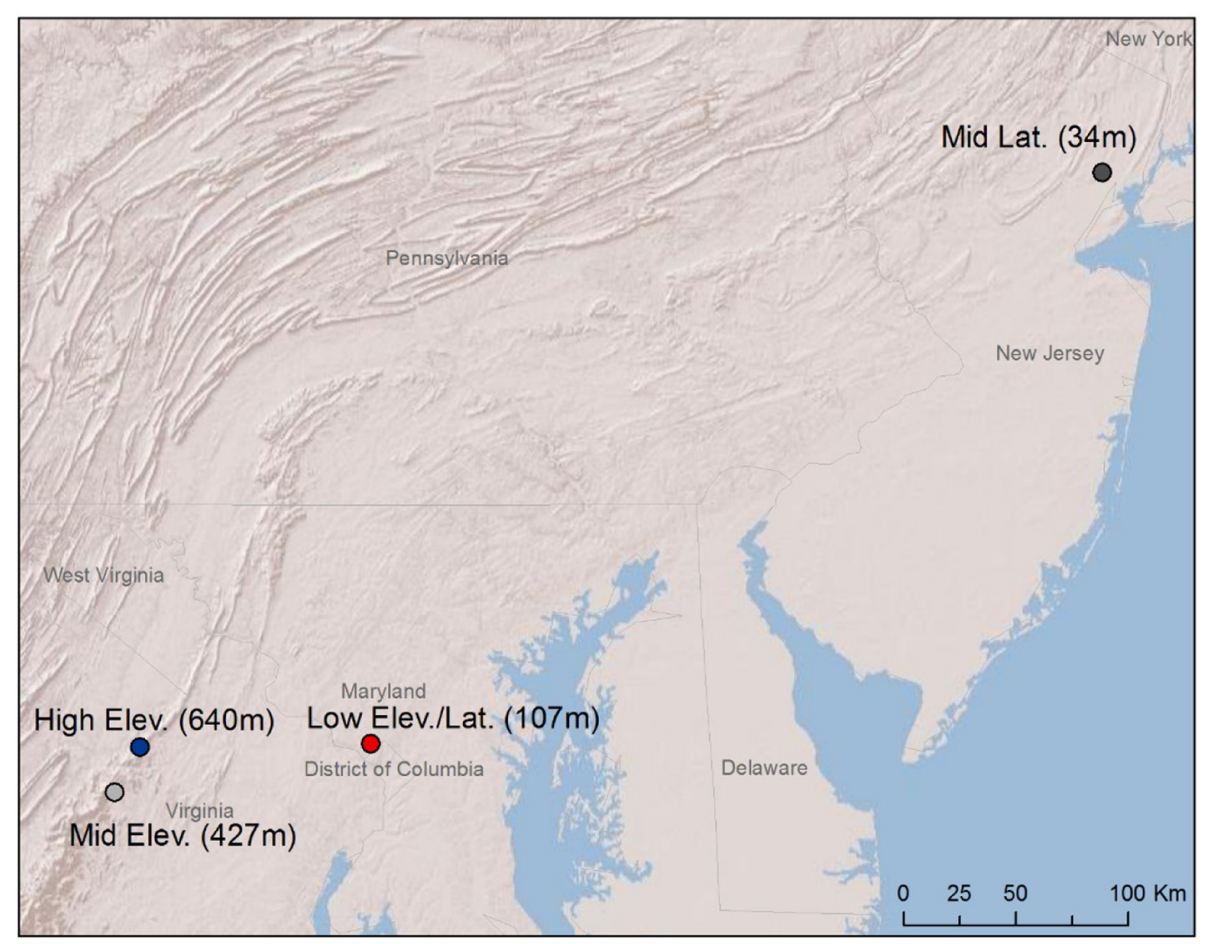

Fig. 1 Map of study sites. Site names describe the latitude and/or elevation for each population of $C$. pipiens relative to the low elevation/latitude population and the elevation height is in parentheses

populations [39], introgression of selected alleles from this tropical species could influence the response of populations to temperature.

\section{Rearing and handling}

All field collected eggs were hatched at $25{ }^{\circ} \mathrm{C}\left( \pm 2{ }^{\circ} \mathrm{C}\right)$ under a photoperiod of 14:10 hrs (L:D), and larvae were morphologically identified to the Cx. pipiens complex using published keys [40]. Larvae were reared at $25{ }^{\circ} \mathrm{C}$ in groups of $\sim 200$ in Sterilite ${ }^{\oplus}$ plastic trays $(27.9 \mathrm{~cm} \mathrm{~L} \times$ $16.8 \mathrm{~cm} \mathrm{~W} \times 7.0 \mathrm{~cm} \mathrm{H}$ ), filled with 1 liter of deionized water. Larvae were fed a finely ground 1:1:1 mixture of $\mathrm{MP}^{\circ}$ Liver Powder Bovine, Kaytee Koi's Choice ${ }^{\bullet}$ Premium Fish Food, \& Small World ${ }^{\circ}$ alfalfa rabbit feed. Adults were transferred to a $30.5 \mathrm{~cm}^{3}$ aluminum mesh collapsible cage (BioQuip) and held at $25^{\circ} \mathrm{C}$. Five dayold mosquitoes were deprived of sucrose, but not water, overnight $(\sim 12-15 \mathrm{~h})$ and then fed a mixture of defibrinated chicken blood (Rockland Immunochemicals) plus a final concentration of $2.5 \%$ sucrose and $1 \%$ ATP, warmed at $37{ }^{\circ} \mathrm{C}$ for $5 \mathrm{~min}$ in a water bath. Females oviposited en masse and we collected an average of 61 egg rafts (20-85 rafts per population). Larvae from each population were pooled together, and 600 larvae from each population were placed into three trays (200 larvae each), except for the high elevation population which only had one tray with 200 larvae. This first laboratory- raised generation of offspring was used for measuring the response of each population to variation in temperature.

We used six fixed temperatures (one per incubator) that spanned the minimum and maximum summer temperatures experienced across study populations: 16, 20, $24,27,31$, and $35{ }^{\circ} \mathrm{C}$. Relative humidity $(70 \pm 10 \%)$ and photoperiod (16:8 h. (L:D)) were held constant in all five incubators and larvae (and adults) were maintained as described above. Each day dead larvae and pupae were counted and removed. However, counts revealed that larvae had also disappeared due to cannibalism. Pupae from replicate trays were combined and transferred to a single emergence jar (BioQuip). The number of emerged males and females was counted daily and adults were immediately transferred to one-gallon cardboard containers with mesh tops. At $35{ }^{\circ} \mathrm{C}$ no larvae survived to become adults. As a result, we used the remaining larvae from the initial rearing temperature $\left(25^{\circ} \mathrm{C}\right)$ to measure adult daily survival and biting rate at $35^{\circ} \mathrm{C}$.

Adult mosquitoes were fed ad libitum Domino ${ }^{\circ}$ sugar cubes and water. We monitored adult mortality by inspecting each cage daily and counted and removed dead adults. Females had constant access to an oviposition site-a small cup filled with deionized water. Blood meals were offered every 2 days for populations in the $35 \& 20{ }^{\circ} \mathrm{C}$ incubators, every 3 days for populations in the 24,27 and $31{ }^{\circ} \mathrm{C}$ incubators, and every 4 days for 
populations in the $16{ }^{\circ} \mathrm{C}$ incubator. We offered blood meals at different intervals in the different temperature treatments due to limited personnel and logistical difficulties, but this reduced our power to detect differences among populations, and should be avoided in future studies, if possible.

\section{Statistical analysis}

All statistical analyses were done in R v3.1.1 (R Development Core Team 2012). We used generalized linear models to quantify the effects of population and temperature on female development time, larval emergence, larval cannibalism, and larval survival, and included two-way interactions between population and temperature to allow for the effect of temperature to vary among populations. We included linear and quadratic terms for temperature because residuals from linear models showed obvious evidence of nonlinearity. We calculated the $\mathrm{Q}_{10}$ temperature coefficient for larval development rate as $(\mathrm{R} 2 / \mathrm{R} 1)^{10 /(\mathrm{T} 2 / \mathrm{T} 1)}$ where $\mathrm{R}$ is the developmental rate and $\mathrm{T}$ is the temperature [41]. We used the fraction of larvae emerging as adults to quantify larval survival rather than survival analyses, because larval death included both individuals that were found dead on a known day, and cannibalism, in which larvae disappeared and the date of larval death from cannibalism could not be determined. We used Cox proportional hazard models with Weibull distributions and right-censored data to analyze differences in female adult survival with temperature among populations [42]. We illustrate population response to temperature using the fraction of adult mosquitoes alive 9 days after emergence, which coincides with average lifespan of $C x$. pipiens in the field for the lowest elevation population [43]. We used generalized linear mixed models with a binomial distribution and a logit link to analyze factors influencing the probability of mosquitoes taking their second blood meal including age, source population, and temperature, as fixed effects, and emergence group, and individual as random effects. For each life history trait, we compared the full fitted model to models that were each missing one fixed effect, by AIC. Finally, we combined the best fitting models for each trait, and models from a previous study [44] to simulate population dynamics. For each population we estimated the number of infectious biting adults (i.e. those taking their second bloodmeal and therefore infectious for WNV) at temperatures $20-35{ }^{\circ} \mathrm{C}$.

\section{Results}

In total, we measured juvenile survival for 9659 individuals $(2415 \pm 976$ (mean \pm SD) per population), development time for 4099 females $(1025 \pm 79)$, adult mortality for 922 females $(230 \pm 56)$, and biting rate for 39 females $(10 \pm 5)$. The best fitting models by AIC for larval and adult survival, and development rate were the full models which included population, temperature, temperature ${ }^{2}$, population"temperature, and population"temperature ${ }^{2}$ (Additional file 1: Tables S1-S4). For biting rate, the best fitting model did not include population or populationtemperature interactions, but did include temperature, age when taking the first blood meal, and the number of days between bloodmeals (Additional file 1: Table S5).

Adult female development time decreased monotonically and nonlinearly with increasing temperature, and the greatest decrease occurred at cold temperatures (Fig. 2). A $4{ }^{\circ} \mathrm{C}$ increase in temperature from 16 to $20{ }^{\circ} \mathrm{C}$ decreased female development time by $57 \%$ (7.8 days) across the four populations, whereas the same $4{ }^{\circ} \mathrm{C}$ increase from 27 to $31{ }^{\circ} \mathrm{C}$ only decreased development time by $10 \%$ (0.85 days) (Fig. 2). Patterns were similar for adult female development rate - the inverse of development time which increased at a decelerating rate with increasing temperature (Additional file 1: Figure S3). The $\mathrm{Q}_{10}$ temperature coefficient decreased with temperature, from 2.1, between 16 and $27^{\circ} \mathrm{C}$, to 1.5 between 20 and $31{ }^{\circ} \mathrm{C}$.

Variation among populations in developmental time and rate were greatest at extreme temperatures, and smaller than the effects of temperature. The low latitude/altitude population had the fastest development rate across all temperatures. Specifically, at $16{ }^{\circ} \mathrm{C}$ the low elevation/latitude population developed 1.9 days (9\%) faster than the high elevation population, and at $31{ }^{\circ} \mathrm{C}$ the low elevation/latitude population developed 1.2 days $(15 \%)$ faster than the high elevation population (Fig. 2 and Additional file 1: Figure S3).

Average daily larval survival over the developmental period decreased almost linearly with increasing temperature until $31{ }^{\circ} \mathrm{C}$ above which it declined more sharply (Fig. 3a). At $35^{\circ} \mathrm{C}$ all larvae died before reaching the fourth instar. Overall, a $15{ }^{\circ} \mathrm{C}$ increase in temperature from $16{ }^{\circ} \mathrm{C}$ to $31{ }^{\circ} \mathrm{C}$ tripled daily mortality from 1 to $3 \%$ per day (Fig. 3a). Variation in daily larval survival among populations was substantial but variable across different temperatures. The low elevation/latitude population had the highest larval daily survival (mortality was 6-fold lower than the coolest high-elevation population) at low temperatures $\left(16{ }^{\circ} \mathrm{C}\right)$ but the 2 nd lowest survival at $31{ }^{\circ} \mathrm{C}$ (mortality was $67 \%$ higher than the mid-latitude population). Additionally, the high elevation population had the highest larval mortality ( 2.2 times greater than the mid-elevation population).

Larval stage survival (the product of average daily survival and larval development time) increased with increasing temperature at temperatures below $27{ }^{\circ} \mathrm{C}$ because development rate increased faster than mortality rate. However, between 31 and $35{ }^{\circ} \mathrm{C}$ stage survival decreased sharply because the increase in daily mortality overwhelmed the smaller decrease in developmental rate (Fig. 3b). Across all four populations, a $4{ }^{\circ} \mathrm{C}$ rise from 16 


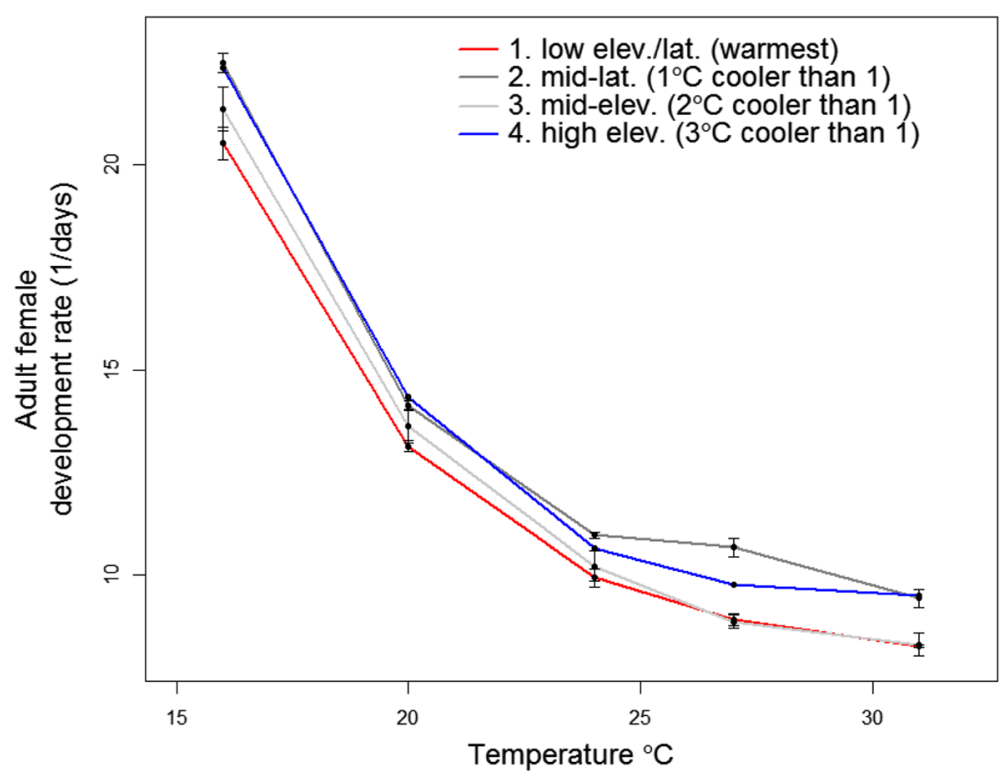

Fig. 2 Adult female development time for Cx. pipiens (egg hatch to female emergence). All larvae died at $35^{\circ} \mathrm{C}$. Error bars show $95 \%$ confidence intervals for replicate flats (200 mosquitoes). For the high population there was only one replicate flat with 200 mosquitoes. Points are jittered along the $x$-axis to facilitate presentation

to $20{ }^{\circ} \mathrm{C}$ increased stage survival by $12 \%$, whereas stage survival decreased by $16 \%$ from 27 to $31^{\circ} \mathrm{C}$ (Fig. 3b). Approximately $67 \%$ of larval mortality was due to larval cannibalism, which showed essentially the same trends as total larval mortality (Additional file 1: Figure S2).

Differences among populations in larval stage mortality were substantial. For example, mortality of the mid- latitude and high elevation populations were twice as high as the low elevation population at $16{ }^{\circ} \mathrm{C}$, and high elevation populations had markedly lower stage survival at most temperatures (Fig. 3). As with patterns across temperatures, these differences among populations in larval stage survival were mostly explained by differences in cannibalism. High elevation larvae were three times
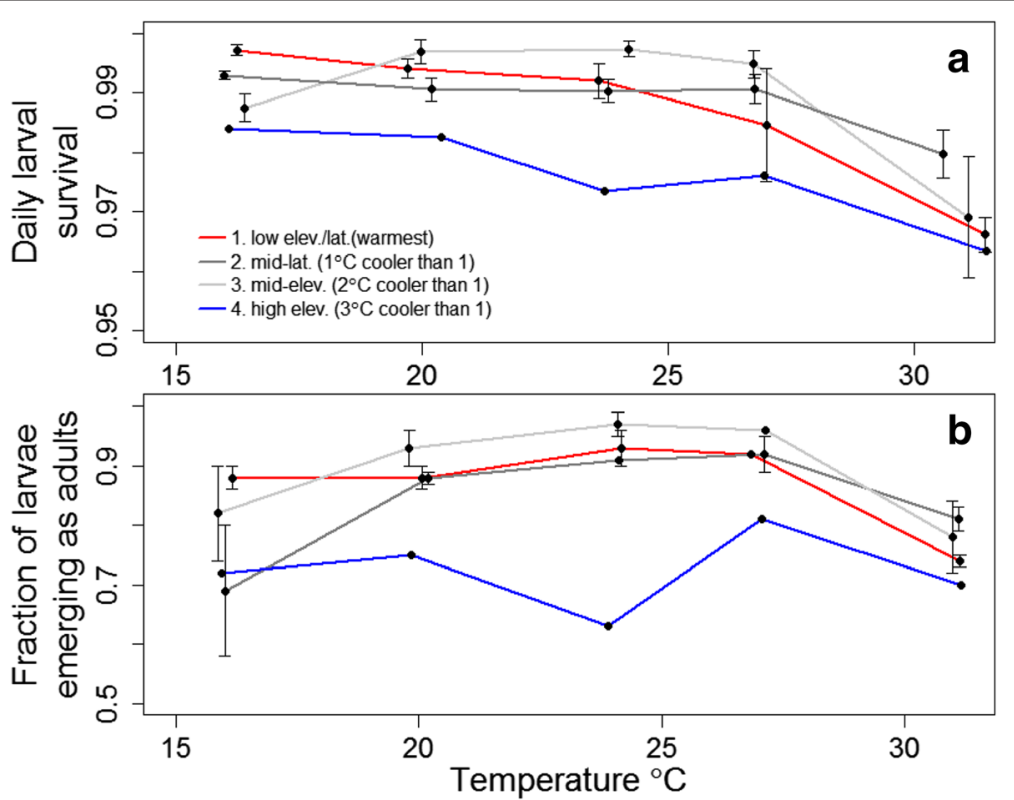

Fig. 3 Cx. pipiens larval survival. All larvae died at $35^{\circ} \mathrm{C}$. Error bars show standard error for replicate flats (200 mosquitoes). For the high population there was only one replicate flat with 200 mosquitoes. Points are jittered along the $\mathrm{x}$-axis to facilitate presentation. a Daily juvenile survival. b Fraction of larvae that survived to emerge as adults 
more likely to be cannibalized than those from the midelevation population, which had the lowest cannibalism and highest overall stage survival across most temperatures (Fig. 3, Additional file 1: Figure S2).

Adult female survival decreased nonlinearly and monotonically with increasing temperature, and, as with larval survival, the largest decrease occurred at higher temperatures (Fig. 4, Additional file 1: Figure S4). For all populations, a $4{ }^{\circ} \mathrm{C}$ rise, from 16 to $20{ }^{\circ} \mathrm{C}$, resulted in a nearly negligible $0.6 \%$ decrease in female survival, whereas, a similar increase in temperature, from 27 to $31{ }^{\circ} \mathrm{C}$ decreased survival $25 \%$ (Fig. 4). Variation among populations was again substantial, with the coldest (highelevation) population having 2.2 fold lower mortality than the warmest low elevation population at $16{ }^{\circ} \mathrm{C}(0.19 \%$ vs. $0.42 \%$ daily mortality resulting in average lifespans of 5.3 and 2.4 days, for the high elevation and low elevation populations, respectively). At $27^{\circ} \mathrm{C}$ the high elevation population had $88 \%$ higher mortality than the mid-elevation population, but at $35{ }^{\circ} \mathrm{C}$ this difference was reversed with the mid-elevation population having a $40 \%$ higher mortality than both the high and low elevation populations which had almost identical survival.

The cumulative fraction of females taking a second blood meal increased linearly with temperature and the number of days between blood meals, but did not differ significantly among populations, possibly due to small sample sizes (Fig. 5a-d). The effect of age on biting rate was also substantial (Additional file 1: Table S5). For example, at $27^{\circ} \mathrm{C}$, the probability that females would take a second blood meal 7 days later increased from 0.15 to 0.88 as the age when they took their first blood meal increased from 2 to 14 days (Fig. 5e).

We integrated the best fitting models described above for each trait, and the extrinsic incubation period for West Nile virus [44], to simulate the number of larvae, adults, and infectious biting adults taking their second blood meal over time for each population and temperature (Fig. 6). For all populations, $24{ }^{\circ} \mathrm{C}$ produced the highest fraction of infectious biting adults (a peak of $11.3 \%$ of the starting larval population occurring 52 days after hatching; Fig. 6a). At warmer temperatures there were fewer infectious biting mosquitoes, but they were produced earlier (at 24 and $31{ }^{\circ} \mathrm{C}$, infectious mosquitoes peaked at 11.3, and $8.0 \%$ of the starting larval population occurred on days 52 and 28 post-hatching, respectively; Fig. 6a). Differences among populations were very large, and the rank order varied with temperature (Fig. 6b). The midelevation population had the highest number of infectious biting adults at $24^{\circ} \mathrm{C}$, which was more than twice as many as the high elevation population at this temperature (Fig. 6b). In contrast, at $31{ }^{\circ} \mathrm{C}$ the mid-latitude population had the highest number of infectious biting adults.

\section{Discussion}

Many studies have quantified the effect of temperature on mosquito life-history traits for single populations of a species [45-48]. As in other studies, we found that temperature had strong and relatively consistent effects among populations on development time, larval survival

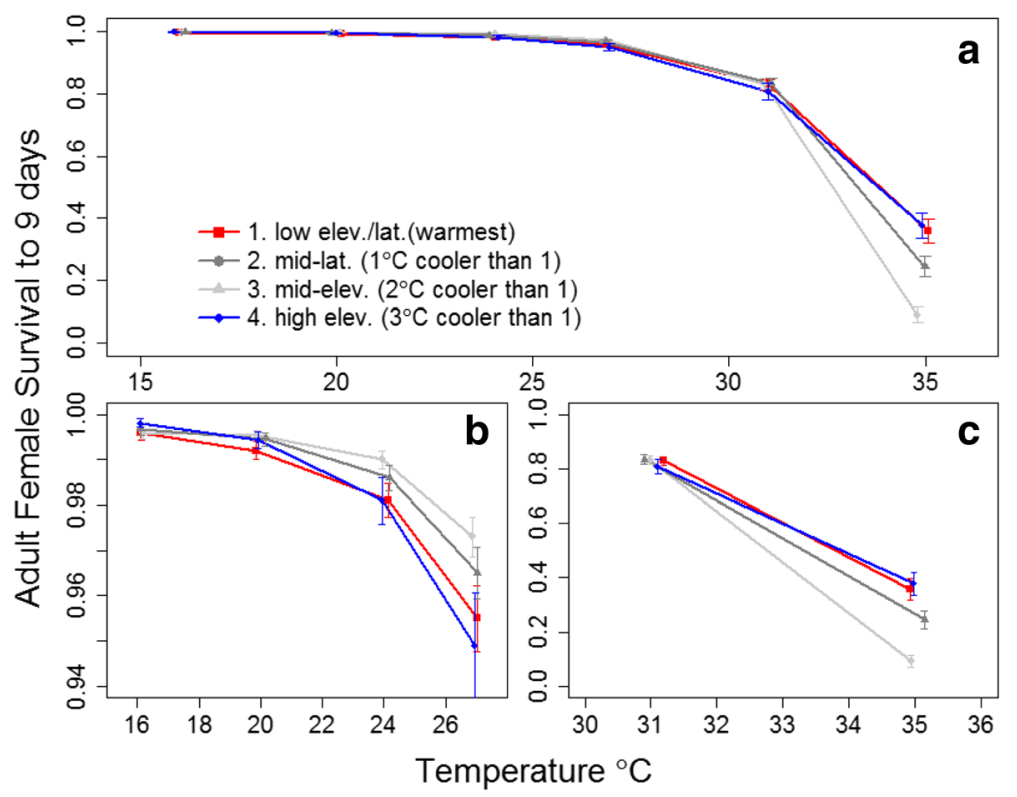

Fig. 4 Estimated survival of adult female Cx. pipiens to 9 days post-emergence based on Cox proportional-hazard models (see Additional file 1: Figure S1 for raw survival plot). Error bars show binomial errors for individual female mosquitoes. Points are jittered along the $x$-axis to facilitate presentation. a Adult female survival from temperature $16-35^{\circ} \mathrm{C}$. b Adult female survival at cooler temperatures $\left(16-27^{\circ} \mathrm{C}\right)$. c Adult female survival ot warmer temperature $\left(31-35^{\circ} \mathrm{C}\right)$. Note variation in y-axes for $\mathbf{b}$ and $\mathbf{c}$. 


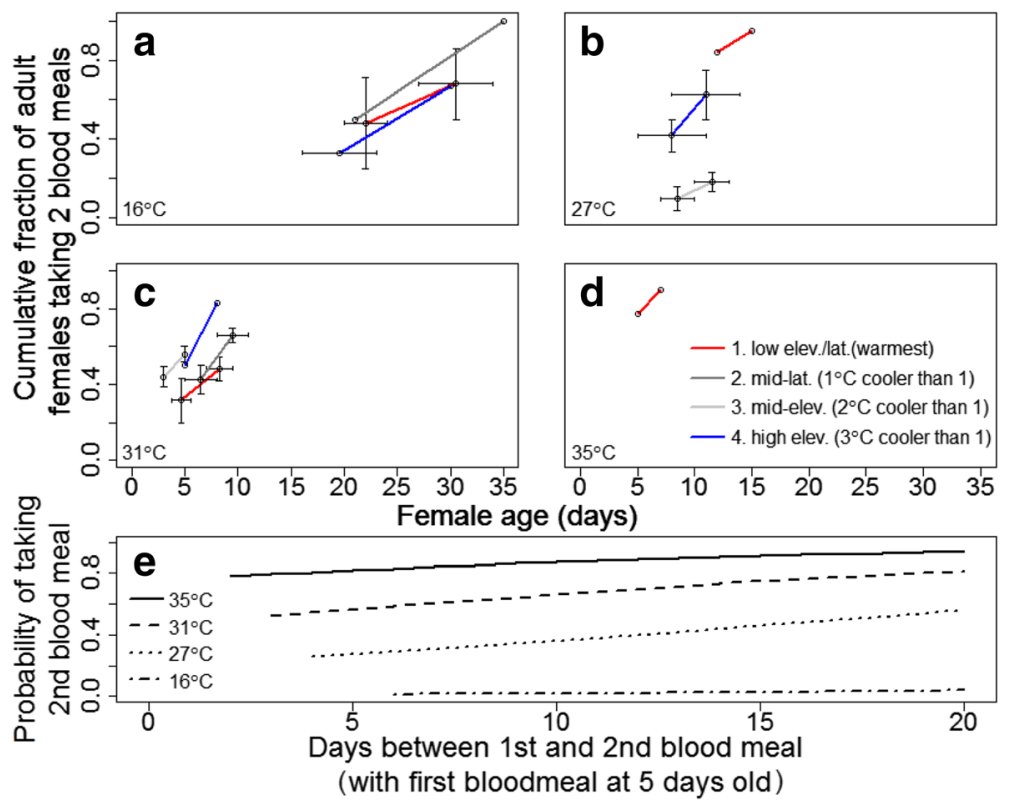

Fig. 5 Cx. pipiens biting rate. a-d Cumulative fraction of females taking two blood meals. Each line represents a group of females that took their first blood meal on the same day. Each group was then followed over time until they took a second blood meal. A y-value of $100 \%$ means that of the initial females who took their first blood meal on the same day all females within that group went on to take a second blood meal before the study was terminated. Error bars are binomial errors based on the number of individuals within a group. e Predicted Generalized Linear Mixed-effects Model values for probability of taking a second blood meal, given that age at first blood meal was 5 days old

and adult survival, the three most well-measured life history traits, and the patterns were strongly nonlinear. Development time, larval survival, and adult survival decreased with increasing temperature, and biting rate increased. Temperature effects were strongest at higher temperatures for survival and at lower temperatures for development and biting rate.

Although the direction of the relationships we observed between temperature and life history traits are mostly consistent with previously observed patterns, the shape of the temperature performance relationships sometimes differed between our results and previous studies. We found that adult survival decreased monotonically with temperature and female development rate increased monotonically with temperature, whereas some previous studies presented unimodal relationships with temperature [49]. It is worth noting that decreases in life history traits at very high temperatures can be due to rapid death of larval or adult mosquitoes rather than a lack of development or gonotrophic cycling, as we also observed for larval development.

We found significant differences among populations in how life history traits varied with temperature. However, these differences were rarely consistent with a local thermal adaptation hypothesis, which was similar to results from a previous study of two populations of Culex tarsalis in California [21]. Some populations of Cx. pipiens had uniformly higher or lower performance for some traits across all temperatures, such as the uniformly faster development rate of the warmest population (Fig. 2) or the uniformly lower larval survival of the coldest population (Fig. 3a). The lower larval survival of the highest elevation population may have been influenced by a low number of egg rafts collected from this site. However, the high survival of adults from this population at high and low temperatures demonstrates that not all traits were lower than other populations. In addition, some populations had the worst performance at temperatures where local adaptation would have resulted in them performing the best and vice-versa (e.g. the warmest population in Fig. 3a). Although studies with a larger number of populations or from across a larger spatial temperature gradient might find some evidence for local thermal adaptation, our results suggest that variation that is uncorrelated with local temperatures is substantial and must be incorporated into uncertainty estimates in efforts to predict spatial and temporal variation in disease under climate change scenarios. Our results, and specifically, the magnitude of the site and site-temperature coefficients, provide an estimate of the magnitude of this variation.

\section{Conclusion}

Our results show that the impact of climate change on mosquitoes will be more variable than previous predictions due to the substantial variation that exists in the response of populations to temperature. At the same 

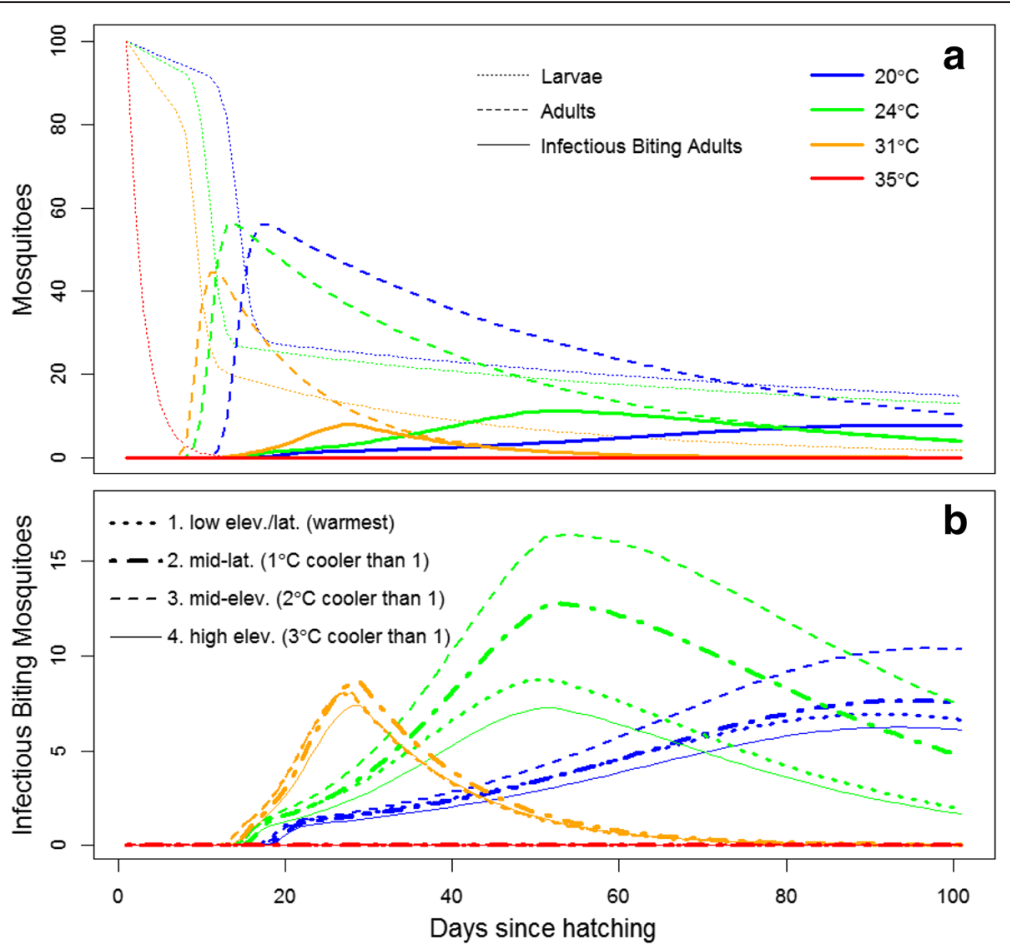

Fig. 6 Simulated population dynamics and vectoral capacity for 100 larval CX. pipiens mosquitoes. a The effect of temperature on the number of larvae emerging as adults and later becoming infectious biting adults, using the average model coefficients across all populations (Additional file 1: Tables S1-S5), and the relationship between temperature and time and the fraction of mosquitoes transmitting West Nile virus [44]. Each line color shows a cohort of 100 mosquitoes over time (hatching on day 0 ) at a specific temperature and line style indicates the mosquito life stage. Comparison of similar line types indicates the effect of temperature. At $35^{\circ} \mathrm{C}$ all larval mosquitoes died before pupation. $\mathbf{b}$ Variation among populations and temperature on the number of infectious biting adults over time starting from 100 larvae on day 0 , as in panel (a). Line color indicates temperature and line style indicates population. Note the difference in y-axis scales in panels (a) and (b)

time, these differences among populations are likely to contribute to spatial variation in transmission, and will be an important source of variation for selection to act on as climate warms $[50,51]$. The combination of standing variation and mosquitoes' evolutionary response will determine the impact of changing climates on vector borne disease.

\section{Additional file}

Additional file 1: Mean monthly temperature for each site from 2005-2010. Data was obtained from the NOAA Climate Data Online site (http://www.ncdc.noaa.gov/cdo-web/). For the high elevation site we calculated the average monthly temperatures using data from the nearby mid-elevation site and the rate of adiabatic cooling with elevation $\left(1.5^{\circ} \mathrm{C}\right.$ lower than the mid-elevation site). (DOCX $145 \mathrm{~kb}$ )

\section{Competing interests}

The authors declare that they have no competing interests.

\section{Authors' contributions}

JR, LDK, and AMK designed the study. JR collected the data. JR and AMK analyzed the data and wrote the first draft. All authors edited, read, and approved the final version of the manuscript.

\section{Acknowledgements}

We thank Rachel Viscio and Amy Matacchiero for assistance with mosquito maintenance and data collection. We also thank Dr. Dina Fonsecca's lab for collection of the mid-latitude Culex pipiens egg rafts. We thank S. Munch, S. Forde, B. Lyon, and the Kilpatrick lab for comments on the manuscript. Funding was provided by NSF-California LSAMP Bridge to the Doctorate grant HRD-0929836, NIH grant 1R01Al090159 and NSF grant EF-0914866.

\section{Author details}

${ }^{1}$ Department Ecology and Evolutionary Biology, University of California, Santa Cruz, CA 95064, USA. ${ }^{2}$ New York State Department of Health, Wadsworth Center, Slingerlands, NY 12159, USA. ${ }^{3}$ State University of New York at Albany, Albany, NY, USA.

Received: 21 September 2015 Accepted: 22 February 2016

Published online: 29 February 2016

\section{References}

1. Patz JA, Hulme M, Rosenzweig C, Mitchell TD, Goldberg RA, Githeko AK, Lele S, McMichael AJ, Sueur D Le: Regional warming and malaria resurgence. Nature. 2002;420(December):12-3.

2. Hay S, Guerra C, Tatem A. The global distribution and population at risk of malaria: past, present, and future. Lancet Infect Dis. 2004;4(June):327-36.

3. Rogers D, Randolph S. The global spread of malaria in a future, warmer world. Science. 2000:289:1763-6.

4. Kilpatrick A, Randolph S. Drivers, dynamics, and control of emerging vector-borne zoonotic diseases. Lancet. 2012:380:1946-55.

5. Chaves LF, Hashizume M, Satake A, Minakawa N. Regime shifts and heterogeneous trends in malaria time series from Western Kenya Highlands. Parasitology. 2012;139:14-25. 
6. Siraj AS, Santos-Vega M, Bouma MJ, Yadeta D, Ruiz Carrascal D, Pascual M. Altitudinal changes in malaria incidence in highlands of Ethiopia and Colombia. Science. 2014;343:1154-8.

7. Githeko AK, Lindsay SW, Confalonieri UE, Patz JA. Climate change and vectorborne diseases: a regional analysis. Bull World Health Organ. 2000;78:1136-47.

8. Lafferty K. The ecology of climate change and infectious diseases. Ecology. 2009;90:888-900.

9. Rogers DJ, Randolph SE. Climate change and vector-borne diseases. Adv Parasitol. 2006;62:345-81

10. Gething PW, Smith DL, Patil AP, Tatem AJ, Snow RW, Hay SI. Climate change and the global malaria recession. Nature. 2010;465:342-5.

11. Sternberg ED, Thomas MB. Local adaptation to temperature and the implications for vector-borne diseases. Trends Parasitol. 2014;30:115-22.

12. Conover DO, Duffy TA, Hice LA. The covariance between genetic and environmental influences across ecological gradients: reassessing the evolutionary significance of countergradient and cogradient variation. Ann N Y Acad Sci. 2009:1168:100-29.

13. Berven K, Gill D, Smith-Gill S. Countergradient selection in the green frog, Rana clamitans. Evolution. 1979;33:609-23.

14. Conover D, Schultz ET. Phenotypic similarity and the evolutionary significance of countergradient variation. Trends Ecol Evol. 1995;10:248-52.

15. Armbruster P, Conn JE. Geographic variation of larval growth in North American Aedes albopictus (Diptera: Culicidae). Ann Entomol Soc Am. 2006;99:1234-43.

16. Levins R. Thermal acclimation and heat resistance in Drosophila species. Am Nat. 1969;103:483.

17. Cheng C, White BJ, Kamdem C, Mockaitis K, Costantini C, Hahn MW Besansky NJ. Ecological genomics of Anopheles gambiae along a latitudinal cline: a population-resequencing approach. Genetics. 2012;190:1417-32.

18. Coluzzi M, Sabatini A, Petrarca V, Di Deco MA. Chromosomal differentiation and adaptation to human environments in the Anopheles gambiae complex. Trans R Soc Trop Med Hyg. 1979;73:483-97.

19. Gray EM, Rocca KAC, Costantini C, Besansky NJ. Inversion 2La is associated with enhanced desiccation resistance in Anopheles gambiae. Malar J. 2009; 8:215.

20. Rocca KAC, Gray EM, Costantini C, Besansky NJ. 2La chromosomal inversion enhances thermal tolerance of Anopheles gambiae larvae. Malar J. 2009;8:147.

21. Reisen WK. Effect of temperature on Culex tarsalis (Diptera: Culicidae) from the Coachella and San Joaquin Valleys of California. J Med Entomol. 1995; 32:636-45.

22. Kilpatrick A, Kramer LD, Campbell SR, Alleyne EO, Dobson AP, Daszak P. West Nile virus risk assessment and the bridge vector paradigm. Emerg Infect Dis. 2005;11:425-9.

23. Hamer GL, Kitron UD, Brawn JD, Loss SR, Ruiz MO, Goldberg TL, et al. Culex pipiens (Diptera: Culicidae): A bridge vector of West Nile virus to humans. J Med Entomol. 2008:45:125-8

24. Turell M, Sardelis M, O'Guinn M, Dohm D. Potential vectors of West Nile virus in North America. In: Current Topics in Microbiology and Immunology. Berlin: Springer; 2002. p. 241-52.

25. Kilpatrick AM, Pape WJ. Predicting human West Nile virus infections with mosquito surveillance data. Am J Epidemiol. 2013;178:829-35

26. Farajollahi A, Fonseca DM, Kramer LD, Marm Kilpatrick A. "Bird biting" mosquitoes and human disease: a review of the role of Culex pipiens complex mosquitoes in epidemiology. Infect Genet Evol. 2011;11:1577-85.

27. Joy J, Clay J. Habitat use by larval mosquitoes in West Virginia. Am Midl Nat. 2002:148:363-75

28. Vinogradova EB. Culex Pipiens Pipiens Mosquitoes: Taxonomy, Distribution, Ecology, Physiology, Genetics, Applied Importance and Control. Sofia -Moscow: Pensoft Publishers; 2000.

29. Kilpatrick A. Globalization, land use, and the invasion of West Nile virus. Science. 2011:334:323-7.

30. Centers for Disease Control and Prevention [http://www.cdc.gov/ncidod/ dvbid/westnile/index.html]

31. LaDeau SL, Kilpatrick AM, Marra PP. West Nile virus emergence and largescale declines of North American bird populations. Nature. 2007:447:710-3.

32. Kilpatrick AM, LaDeau SL, Marra PP. Ecology of West Nile virus transmission and its impact on birds in the western hemisphere. Auk. 2007:124:1121-36.

33. Kilpatrick AM, Peters RJ, Dupuis AP, Jones MJ, Daszak P, Marra PP, Krame LD: Predicted and observed mortality from vector-borne disease in wildlife: West Nile virus and small songbirds. Biol Conserv. 2013;165:79-85.

34. Confalonieri U, et al. Climate Change 2007: Impacts, Adaptation and Vulnerability. In: Parry ML, Canziani OF, Palutikof JP, Linden PJvd, Hanson CE, editors. Contribution of Working Group II to the Fourth Assessment Report of the Intergovernmental Panel on Climate Change. Cambridge, UK: Cambridge Univ Press; 2007. p. 391-431.

35. Byars SG, Papst W, Hoffmann AA. Local adaptation and cogradient selection in the alpine plant, Poa hiemata, along a narrow altitudinal gradient. Evolution. 2007:61:2925-41.

36. Brown JJ, Ehtisham A, Conover DO. Variation in larval growth rate among striped bass stocks from different latitudes. Trans Am Fish Soc. 1998;127:598-610.

37. Kothera L, Zimmerman EM, Richards CM, Savage HM. Microsatellite characterization of subspecies and their hybrids in Culex pipiens Complex (Diptera: Culicidae) Mosquitoes Along a North-South Transect in the Central United States. J Med Entomol. 2009:46:236-48.

38. Smith JL, Fonseca DM. Rapid assays for identification of members of the Culex (Culex) pipiens complex, their hybrids, and other sibling species (Diptera: cCulicidae). Am J Trop Med Hyg. 2004;70:339-45.

39. Kilpatrick AM, Kramer LD, Jones MJ, Marra PP, Daszak P, Fonseca DM. Genetic influences on mosquito feeding behavior and the emergence of zoonotic pathogens. Am J Trop Med Hyg. 2007;77:667.

40. Darsie R, Ward R. Identification and Geographical Distribution of the Mosquitoes of North America. North of Mexico: University Press of Florida; 2005.

41. Bennett AF. Temperature and muscle. J Exp Biol. 1985:115:333-44.

42. Cox DR, Society S, Methodological SB. Regression Models and Life-Tables. J R Stat Soc Ser B. 2007;34:187-220.

43. Jones CE, Lounibos LP, Marra PP, Kilpatrick AM. Rainfall influences survival of Culex pipiens (Diptera: Culicidae) in a residential neighborhood in the mid-Atlantic United States. J Med Entomol. 2012;49:467-73.

44. Kilpatrick AM, Meola MA, Moudy RM, Kramer LD. Temperature, viral genetics, and the transmission of West Nile virus by Culex pipiens mosquitoes. PLoS Pathog. 2008;4:e1000092.

45. Ciota A, Matacchiero A, Kilpatrick AM, Kramer LD. The effect of temperature on life history traits of Culex mosquitoes. J Med Entomol. 2014:51:55-62.

46. Rueda L, Patel K, Axtell R, Stinner R. Temperature-dependent development and survival rates of Culex quiquefasciatus and Aedes aegypti (Diptera: Culicidae). J Med Entomol. 1990;27:892-8.

47. Maharaj R. Life table characteristics of Anopheles arabiensis (Diptera: Culicidae) under simulated seasonal conditions. J Med Entomol. 2003;40: 737-42.

48. Delatte H, Gimonneau G, Triboire A, Fontenille D. Influence of temperature on immature development, survival, longevity, fecundity, and gonotrophic cycles of Aedes albopictus, vector of chikungunya and dengue in the Indian Ocean. J Med Entomol. 2009;46:33-41.

49. Mordecai EA, Paaijmans KP, Johnson LR, Balzer C, Ben-Horin T, de Moor E, McNally A, Pawar S, Ryan SJ, Smith TC, Lafferty KD. Optimal temperature for malaria transmission is dramatically lower than previously predicted. Ecol Lett. 2013;16:22-30.

50. Egizi A, Fefferman NH, Fonseca DM, Fefferman NH: Evidence that implicit assumptions of "no evolution" of disease vectors in changing environments can be violated on a rapid timescale. Philos Trans R Soc B-Biological Sci. 2015;370:20140136.

51. Rohr JR, Dobson AP, Johnson PTJ, Kilpatrick AM, Paull SH, Raffel TR, Ruiz-Moreno D, Thomas MB: Frontiers in climate change-disease research. Trends Ecol Evol. 2011;26:270-7.

\section{Submit your next manuscript to BioMed Central and we will help you at every step:}

- We accept pre-submission inquiries

- Our selector tool helps you to find the most relevant journal

- We provide round the clock customer support

- Convenient online submission

- Thorough peer review

- Inclusion in PubMed and all major indexing services

- Maximum visibility for your research

Submit your manuscript at www biomedcentral com/submit
C BioMed Central 